OPEN ACCESS

Edited by:

Yong Zhu,

East Carolina University, USA

Reviewed by:

T. John Wu,

Uniformed Services University of the

Health Sciences, USA

Watanabe Gen,

Tokyo University of Agriculture and

Technology, Japan

*Correspondence:

Tomoko Soga

tomoko.soga@monash.edu

Specialty section:

This article was submitted to

Experimental Endocrinology,

a section of the journal

Frontiers in Endocrinology

Received: 31 July 2015

Accepted: 26 October 2015

Published: 10 November 2015

Citation:

Soga T, Teo CH, Cham KL, Idris MM and Parhar IS (2015) Early-Life Social Isolation Impairs the GonadotropinInhibitory Hormone Neuronal Activity and Serotonergic System in

Male Rats.

Front. Endocrinol. 6:172. doi: 10.3389/fendo.2015.00172

\section{Early-Life Social Isolation Impairs the Gonadotropin-Inhibitory Hormone Neuronal Activity and Serotonergic System in Male Rats}

\author{
Tomoko Soga*, Chuin Hau Teo, Kai Lin Cham, Marshita Mohd Idris and Ishwar S. Parhar \\ Brain Research Institute, School of Medicine and Health Sciences, Monash University, Selangor, Malaysia
}

Social isolation in early life deregulates the serotonergic system of the brain, compromising reproductive function. Gonadotropin-inhibitory hormone $(\mathrm{GnlH})$ neurons in the dorsomedial hypothalamic nucleus are critical to the inhibitory regulation of gonadotropin-releasing hormone neuronal activity in the brain and release of luteinizing hormone by the pituitary gland. Although $\mathrm{GnlH}$ responds to stress, the role of $\mathrm{GnlH}$ in social isolation-induced deregulation of the serotonin system and reproductive function remains unclear. We investigated the effect of social isolation in early life on the serotonergic-GnlH neuronal system using enhanced green fluorescent protein (EGFP)-tagged $\mathrm{GnlH}$ transgenic rats. Socially isolated rats were observed for anxious and depressive behaviors. Using immunohistochemistry, we examined c-Fos protein expression in EGFP-GnlH neurons in 9-week-old adult male rats after 6 weeks post-weaning isolation or group housing. We also inspected serotonergic fiber juxtapositions in EGFP-GnIH neurons in control and socially isolated male rats. Socially isolated rats exhibited anxious and depressive behaviors. The total number of EGFP-GnlH neurons was the same in control and socially isolated rats, but c-Fos expression in GnlH neurons was significantly reduced in socially isolated rats. Serotonin fiber juxtapositions on EGFP-GnIH neurons were also lower in socially isolated rats. In addition, levels of tryptophan hydroxylase mRNA expression in the dorsal raphe nucleus were significantly attenuated in these rats. These results suggest that social isolation in early-life results in lower serotonin levels, which reduce $\mathrm{G} n \mathrm{IH}$ neuronal activity and may lead to reproductive failure.

Keywords: GnRH, dorsomedial hypothalamus nuclei, serotonin, social stress, dorsal raphe nuclei

\section{INTRODUCTION}

Gonadotropin-releasing hormone $(\mathrm{GnRH})$ and the newly identified neuropeptide gonadotropin-inhibitory hormone $(\mathrm{GnIH})$ are regulators of reproductive activity in vertebrates (1). $\mathrm{GnIH}$ neuropeptides contain an Arg-Phe- $\mathrm{NH}_{2}$ motif [LPXRFamide ( $\mathrm{X}=\mathrm{L}$ or $\left.\mathrm{Q}\right)$ sequence] at their $\mathrm{C}$ termini in most vertebrate species. Rat LPXRFamide peptides are known as RFamiderelated peptides (RFRPs; RFRP-1 and -3) (2). GnIH-expressing cells are mainly located in the 
dorsomedial hypothalamic nucleus $(\mathrm{DMN})$ in rats $(3,4)$ and send fiber projections to GnRH neurons in the pre-optic area (POA), median eminence, and other areas of the brain in rodents (5-8). GnIH acts on GnRH neurons through its seven-transmembrane domain $G$ protein-coupled receptor (GPR) $147(7,9)$.

Recent studies have demonstrated that GnIH neuronal activity is linked to the hypothalamic-pituitary-adrenal (HPA) axis, since glucocorticoids can stimulate gnih mRNA expression (10-12). Our recent study (8) showed that exposure to the glucocorticoid receptor agonist dexamethasone during early life increases $\mathrm{GnIH}$ expression, $\mathrm{GnIH}$ receptor expression, and the number of fiber projections to the POA in adult female mice. These findings suggest that the GnIH system is sensitive to glucocorticoids, which can influence GnRH neuronal activity and reproduction.

Stress and glucocorticoids modulate the serotonin [5-hydroxytryptamine (5-HT)] system in the brain. Several lines of evidence suggest that 5-HT can modulate GnIH neuronal activity. Cellular localization of $5-\mathrm{HT}_{1 \mathrm{~A}}$ receptors is evident in the $\mathrm{DMN}$, where GnIH neurons reside in the rat brain (13). In fact, 5-HT

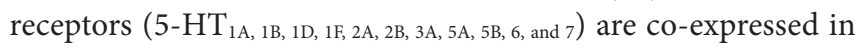
GnIH neurons in the DMN (14). Acute glucocorticoid treatment can cause 5 -HT to accumulate in the DMN $(15,16)$ and treatment with the antidepressant citalopram can stimulate the GnIH system in male mice (14). The 5-HT system of the brain modulates sexual behavior, sexual arousal, and motivation in rodents (17); thus, 5-HT-GnIH signaling may participate in the negative regulation of reproductive activity, including sexual behavior.

Social isolation, a passive stress, activates the HPA axis $(18,19)$, causes imbalances in 5 -HT turnover in rats $(20)$ and decreases the number of 5-HT neurons, expression of 5-HT receptors, number of 5-HT fiber projections in the hippocampus (21-23) and binding activity of the $5-\mathrm{HT}_{1 \mathrm{~A}}$ receptor (24). Indeed, social isolation in early life impairs 5 -HT-associated functions of the brain, which include the control of anxiety, depression, aggression (22, 25-27), and sexual behavior in adult male rats (28-30). Furthermore, social isolation results in a significantly higher level of plasma testosterone $(31,32)$ and increased testis weight (32) in male rats. Social isolation in early life may affect the production of sex steroids and related behaviors, such as sexual behavior and aggression. The neuronal mechanism underlying early-life social isolation-induced reproductive failure through the deregulation of 5-HT and the $\mathrm{GnIH}$ system remains unknown.

We examined the activity of GnIH neurons in our newly created enhanced green fluorescent protein (EGFP)-GnIH transgenic rats. We measured 5-HT fiber juxtapositions to and c-Fos protein expression in GnIH neurons using immunohistochemistry and mRNA levels of the 5-HT associated genes, serotonin transporter (sert) and tryptophan hydroxylase 2 (tph2), using real-time polymerase chain reaction (PCR) in male rats socially isolated in early life. The examination of this model of social isolation in early life may improve our understanding of mental disorders, as well as sexual dysfunction caused by passive stress, in young adults.

\section{MATERIALS AND METHODS}

\section{Animals}

Male transgenic Wistar rats expressing enhanced green fluorescent protein (EGFP) under rat GnIH promoter (GnIH-EGFP transgenic rats) (4), after weaning (3 weeks of age), were randomly assigned to group housing (2-4 male littermates per cage) ( $n=63)$ or individual housing (isolated) condition $(n=65)$ up to 9 weeks of age. The animals were maintained under a controlled $12 \mathrm{~h} \mathrm{light/dark} \mathrm{cycle} \mathrm{(lights} \mathrm{on} \mathrm{from} \mathrm{12:00} \mathrm{a.m.} \mathrm{to} \mathrm{12:00} \mathrm{p.m.)} \mathrm{with}$ temperature maintained at $22^{\circ} \mathrm{C}$ in the SPF animal facility for 6 weeks prior to sampling. Autoclaved water and food were available ad libitum to the rats. Body weight of each rat was measured once a week. All aspects of animal welfare and experiments were in accordance with the guidelines and authorization of Monash University Animals Ethics Committee, AEC (MARP/2012/140, MARP/2013/041).

\section{Anxiety and Depression-Like Behavior Tests}

The open field test (OFT) was conducted in an open field area made up of a black box (width: $1.2 \mathrm{~m}$, length: $1.2 \mathrm{~m}$, and height: $0.30 \mathrm{~m}$ ) for use with white rats of 9 weeks old. A handheld camcorder (Sony Corp., Japan) was used to record the movement of the rat in the arena. The OFT experiments were performed in light (white lighting, 10:00 a.m.-12:00 p.m.) and dark conditions (red lighting, 3:00-6:00 p.m.). The video file from the camcorder was analyzed using an automated motion detector software (Lolitrack v2.0, Loligo Systems, Denmark) to track the movements of the rat. Control rats (group housed; $n=11 /$ light phase and $n=9 /$ night phase) and isolated rats ( $n=12 /$ light phase and $n=13 /$ night phase) were subjected to OFT for $30 \mathrm{~min}$ in order to observe anxiety-like behavior in the dark phase and light phase. The total distance traveled $(\mathrm{cm})$, total time of activity (s), total number of center intrusions, and total time spent in center (s) were measured.

Forced swimming test (FST) was carried out using an automated behavior analytical system (MicroAct system, Neuroscience, Inc., Tokyo, Japan). FST was carried out twice; a pre-test as a habituation session and the actual test was performed $24 \mathrm{~h}$ later. The FST apparatus consisted of a glass cylinder (height: $45 \mathrm{~cm}$ and diameter: $20 \mathrm{~cm}$ ) which was surrounded by round coil. Prior to the FST, the glass cylinder was filled with water $\left(25 \pm 1^{\circ} \mathrm{C}\right)$ to a depth of $30 \mathrm{~cm}$, and a magnet (diameter: $1 \mathrm{~mm}$ and length: $3 \mathrm{~mm}$ ) was taped to each front paw of the rats. Individual rat was gently lowered into the water-filled glass cylinder for a $7 \mathrm{~min}$ swim test. Electrical currents were generated in the coils corresponding to the movements of the magnet taped to the front paws. The currents were amplified, transformed into voltage, and recorded by the system. The duration of immobility was detected automatically using the MicroAct ${ }^{\mathrm{TM}}$ Scratch software (Neuroscience, Inc., Tokyo, Japan). Twenty-six male rats were randomly allocated to group-housing conditions $(n=17)$ or isolated conditions $(n=9)$ and used in the FST.

The sucrose preference test (SPT) was conducted over a period of 5 days. Prior to the test, the rats were habituated to 
the presence of two water bottles in their cages for a minimum of 5 days beforehand. The rats undergoing the experiment were provided with two water bottles: one containing sucrose water (sucrose powder diluted in distilled water, $200 \mathrm{~mL}$ ) and the other containing only distilled water $(200 \mathrm{~mL})$. The concentration of the sucrose water was increased every day over a period of 5 days $(0,0.25,0.5,1.0$, and $2.0 \%)$. Water consumption was measured at 12:00 p.m. everyday by weighing the water bottles to determine consumption by weight. The position of the water bottles was swapped daily at the time of measurement to reduce preference bias in the results. The data for percentage of sucrose consumed against total water consumed was calculated from the results and used as an indicator for sucrose preference. A repeated measures test was used for statistical analysis in order to confirm any significant difference between group-housed and isolated rats in their pattern of sucrose preference over the 5-day test period. Thirty-one male rats were randomly allocated to group-housing conditions $(n=14)$ or isolated conditions $(n=17)$ at 9 weeks of age. We divided the control and the post-weaning social isolation rats each into two groups for three behavioral tests. Group I was used for OFT and FST and group II was tested for SPT.

\section{Polymerase Chain Reaction}

Control $(n=6)$ and socially isolated rats $(n=6)$ at 9 weeks of age were deeply anaesthetized with an intraperitoneal injection of ketamine xylazine $(4.5 \mathrm{mg} / \mathrm{kg} / \mathrm{BW})$ followed by rapid removal of the brain and immediately dissected by $1 \mathrm{~mm}$ rat brain slicer (Neuroscience, Inc., Japan). The POA (bregma +1.2 to -0.12 ) and dorsal raphe (bregma -6.96 to -8.16 ) areas were collected with a sterile blade. Total RNA from these tissues was extracted using TRIzol (Invitrogen, Carlsbad, CA, USA) and transcribed using High Capacity Transcription Kit (Applied Biosystems, Foster City, CA, USA) according to the manufacturer's protocols. Quantitative real-time PCR (ABI 7300, Applied Biosystems Foster City, CA, USA) was performed using primers for gnrh, gnih, sert, tph, and IMPDH2 (0.2M, Table S1 in Supplementary Material) in a final volume of $10 \mu \mathrm{l}$ of $2 \mathrm{X}$ Power SYBR Green PCR mix (Applied Biosystems). The house keeping gene, IMPDH2 is listed as a reference gene in real-time PCR to show geometric average expression level (33). The resulting PCR products were validated using an ABI PRISM 310 Genetic Analyzer and Sequence Analysis Software (Applied Biosystems) and ran on a 2.5\% agarose gel with ethidium bromide used for visualization.

\section{Immunohistochemistry}

Immunocytochemistry for cFos, 5-HT, and 5- $\mathrm{HT}_{2 \mathrm{~A}}$ was performed on the DMN sections obtained through coronal sectioning $(30 \mu \mathrm{m})$. The perfusion fixed (4\% PFA) brain tissue sections were washed with $0.1 \mathrm{M}$ PBS, in an incubation chamber for $10 \mathrm{~min}$ at room temperature and gently shaken at $60 \mathrm{rpm}$. The sections were then incubated in a blocking solution $(40 \mu \mathrm{L}$ normal goat serum (NGS), $10 \mu \mathrm{l} 0.5 \%$ Triton-X, and $1950 \mu \mathrm{l} \mathrm{PBS}$ in $2 \mathrm{~mL} /$ well) for $1 \mathrm{~h}$ in the same conditions as above. After washing, the sections were incubated with polyclonal rabbit anti-c-Fos antiserum diluted 1:600 (sc52, Santa Cruz Biotechnology, Inc., USA), goat anti-5HT antiserum diluted 1:1000 (20079, Immunostar Inc., WI, USA), rabbit anti-5 $\mathrm{HT}_{2 \mathrm{~A}}$ antiserum diluted 1:200 (24288,
Immunostar Inc., WI, USA) in $2 \mathrm{~mL} 0.1 \mathrm{MPBS}$ containing $2 \% \mathrm{NGS}$, $0.5 \%$ Triton-X/well for $24 \mathrm{~h}$ at $4^{\circ} \mathrm{C}$ for c-Fos, $5-\mathrm{HT}$ and $5-\mathrm{HT}_{2 \mathrm{~A}}$ respectively at $4^{\circ} \mathrm{C}$. Next, the sections were washed in $0.1 \mathrm{M}$ PBS incubated in biotinylated anti-rabbit immunoglobulin G (IgG) or biotinylated anti-goat IgG (Vectastain ABC Elite kit, Vector Laboratories, Burlingame, CA, USA) for $45 \mathrm{~min}$. Subsequently, the sections were incubated with avidin-biotinylated horseradish peroxidase complex for $45 \mathrm{~min}$ (Vectastain ABC Elite kit, Vector laboratories, Burlingame, CA, USA). Sections were visualized with Alexa Fluor 594 streptavidin conjugates (S32356, Invitrogen Corporation, USA) and pasted on microscope slides (Superfrost PLUS, Fisher Scientific, Pittsburgh, PA, USA). Mounting medium was applied (VectaShield, Vector Laboratories) followed by coverslips. The number of immunoreactive EGFP-GnIH cells within the DMN were determined using the laser scanning confocal microscope (C1si, Nikon, Tokyo, Japan), equipped with NIS-Element 4.0 Advance software. The specificity of both c-Fos and 5-HT antibody was tested using the rat brain from previous study (4). We divided the control and the post-weaning social isolation rats each into two groups. Group I was used for c-Fos, 5-HT (control: $n=20$, isolated condition: $n=17$ ) and group II was tested for $5-\mathrm{HT}_{2 \mathrm{~A}}(n=3)$. Double-labeled images of c-Fos and $\mathrm{GnIH}$ staining, viewed under the red channel were converted to magenta. The brightness and the contrast were adjusted using Adobe Photoshop CS2 (Adobe, San Jose, CA, USA).

\section{Confocal Analysis of c-Fos Expression and 5-HT Fiber Juxtapositions to GnIH Neurons}

The procedure for confocal analysis of c-Fos expression in $\mathrm{GnIH}$ neurons has been described previously (4). Briefly, immunoreactive c-Fos positive $\mathrm{GnIH}$ neurons were visualized using digitized images captured with a Nikon-30 confocal microscope (C1si, Nikon Instruments Inc., Tokyo, Japan). The total number of GnIH neurons and immunoreactive c-Fos positive GnIH neurons were determined using $0.225 \mu \mathrm{m} \mathrm{Z}$-steps in 10-15 sections which included all EGFP-GnIH neurons in the DMN. To confirm the colocalization of c-Fos in GnIH neurons, the Z-steps were carefully inspected with $3 \mathrm{D}$ image rotation using NIS Elements AR Version 4.0 (Nikon Instruments Inc.). We then calculated the percentage of c-Fos positive GnIH neurons. Only cells with visible nuclei were counted. The procedure for confocal analysis of fiber projections to $\mathrm{GnIH}$ neurons has been described previously (4). Briefly, 5-HT fiber juxtapositions were captured with a confocal microscope at $0.225 \mu \mathrm{m} Z$ Z-steps using $60 \times$ water immersion objective lens, $4 \times$ digital zoom function to cover the entire depth of the neuron (ECLIPSE 90i, Nikon instruments Inc., Japan). Scans of 488 and $543 \mathrm{~nm}$ excitation wavelength were also performed sequentially across optical sectioning to avoid bleed-through between the channels. The number of $\mathrm{GnIH}$ neurons with intimate 5-HT fiber juxtapositions was determined in 10-15 sections to include all EGFP-GnIH neurons in the DMN. To confirm close juxtapositions between 5-HT fibers and GnIH neurons, the Z-steps were carefully inspected with 3D rotation image using NIS Elements AR Version 4.0 (Nikon Instruments Inc.). GnIH neurons with 5-HT fiber juxtapositions on the cell soma or dendrites were 
counted. A contact was scored only if 5-HT fiber varicosity was in direct contact with the GnIH neuron. The percentage of $\mathrm{GnIH}$ neurons with visible nuclei in the DMN and with at least one close juxtapositions with 5-HT fiber was calculated.

\section{Statistics}

Data are presented as means \pm SEM in all bar graphs. Behavioral data were analyzed by two-way apposition using SPSS 20 (IBM, Chicago, IL, USA). SPT was analyzed by a univariate repeated measures using SPSS 20. Immunohistochemistry and gene expression results were analyzed using the Student's $t$-test. Significance was set as $p<0.05$.

\section{RESULTS}

\section{Social Isolation, Anxiety, Depression, and the Serotonin System}

After 6 weeks of social isolation, we conducted three behavioral tests and took samples of brain tissues for biological study (Figure 1A). Although the total distance traveled $(\mathrm{cm})$, total time
A Birth

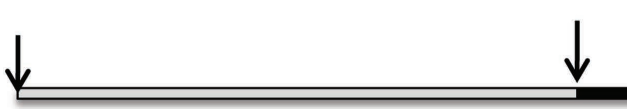

weaning
P63

Post weaning social

isolation (6weeks)

Group1 : OFT

Group2 : FST

Group3 : SPT

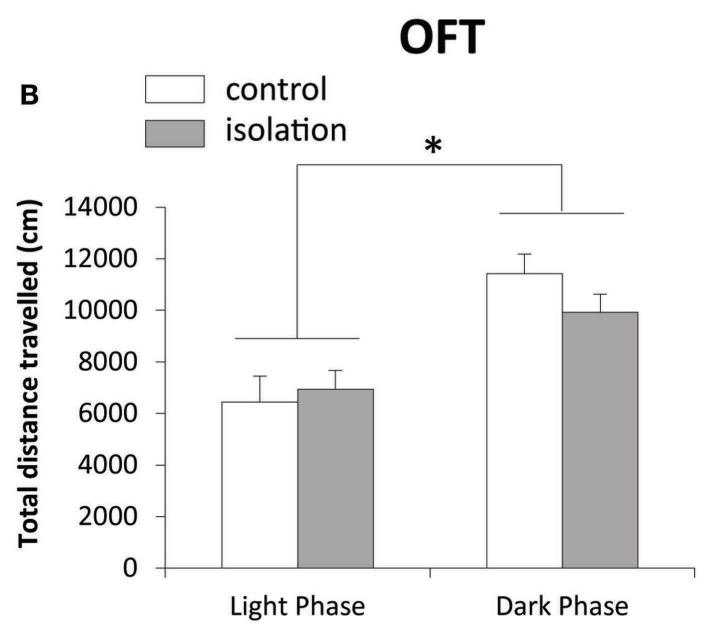

FST

D

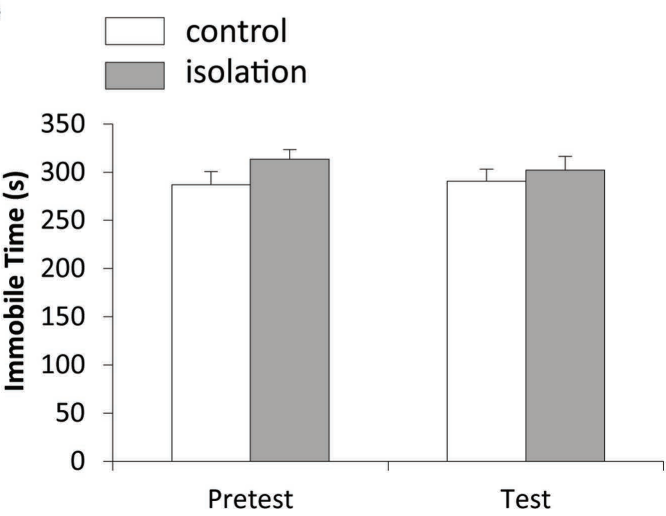

\section{OFT}
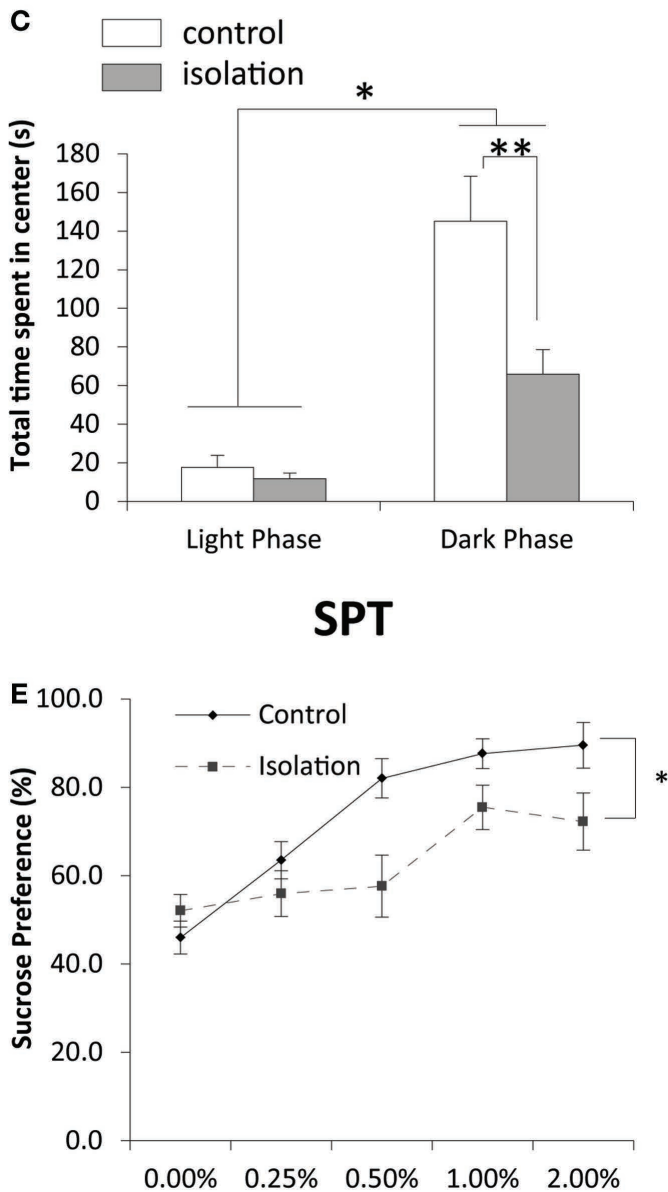

FIGURE 1 | The effect of post-weaning social isolation on behavior. (A) Experimental timeline of social isolation and sampling for four experiments. (B) Total distance traveled in an open field test (OFT) in the light (CT8-10) and dark (CT15-18) phases in control and socially isolated rats (light-phase control: $n=11$, light phase isolated: $n=12$, dark-phase control: $n=9$, dark-phase isolated: $n=13$ ). (C) Total time spent in the center during the OFT (s) in the light and dark phases in control and socially isolated rats. (D) Time spent immobile during a forced-swim test for 7 min (control: $n=9$ and isolated: $n=17$ ). (E) Comparison of sucrose preference was expressed as a percentage of consumption in control $(n=14)$ and isolated $(n=17)$ rats. Data are presented as mean \pm SEM for each set. ${ }^{*} p<0.05$ and ${ }^{* *} p<0.01$ 
of activity (s), total number of intrusions into the center, and total time spent in the center (s) were not significantly different between control and isolated rats, both control and isolated rats traveled more and were active for longer durations in the dark phase compared with the light phase (Figure 1B). No significant difference in activity in the light phase was evident between control and isolated animals (Figure 1B). However, the total time spent in the center by socially isolated rats was significantly shorter in the dark phase than in controls (control: $145.11 \pm 23.28 \mathrm{~s}$, isolated: $65.85 \pm 12.73 \mathrm{~s}, p<0.05$; Figure 1C). Control $(n=17)$ and isolated $(n=9)$ rats were subjected to a forced-swim test for $7 \mathrm{~min}$ to measure time spent immobile. A pre-test was conducted $24 \mathrm{~h}$ earlier for habituation. No significant difference was observed in time spent immobile between control and isolated rats during the pre-test or test sessions (Figure 1D). The difference in sucrose consumption between groups was measured over 5 days. Using a univariate repeated measures test for analysis, a significant difference was observed in sucrose preference between control and isolated rats [control: $F(1,31)=6.168, p<0.05$; Figure 1E].

\section{Social Isolation and Reproduction}

There was no difference in body weight post-weaning between controls and socially isolated male rats (Figure 2A). The level of gnrh mRNA in the POA was significantly lower in socially isolated rats compared with controls (control: $1 \pm 0.2$ and isolated: $0.29 \pm 0.2, p<0.05$; Figure 2B). However, there was no difference in the expression of gnih mRNA in the hypothalamus between socially isolated and control rats (Figure 2B).

\section{Social Isolation and Gonadotropin- Inhibitory Hormone Neuronal Activity}

EGFP-GnIH cell bodies were visible in the DMN, which comprised the central, ventral, and dorsal portions of the DMN, and in the dorsal tuberomammillary nucleus (DTM). There was no significant difference in the total number of EGFP-GnIH cells in the entire DMN and DTM between isolated males and grouphoused control males [control: $1561.43 \pm 156.72(n=14)$ and isolated: $1457.55 \pm 244.48(n=11)$; Figure $3 \mathbf{A}]$. To study the effect of social isolation on GnIH neuronal activity, c-Fos immunoreactivity was analyzed in GnIH neurons using a laser scanning confocal microscope. The percentage of GnIH cells exhibiting c-Fos immunoreactivity in the entire DMN was significantly decreased in isolated males compared with group-housed control males (control: $7.01 \pm 2.2 \%$ and isolated: $1.68 \pm 0.77 \%, p<0.05$; Figures 3B,C).

\section{Social Isolation and Serotonergic Regulation of Gonadotropin-Inhibitory Hormone Cells}

$5-\mathrm{HT}_{2 \mathrm{~A}}$-positive cells were evident in the DMN. Some EGFP$\mathrm{GnIH}$ neurons co-expressed 5- $\mathrm{HT}_{2 \mathrm{~A}}$ (Figures 4A-C). In addition, close juxtapositions between 5-HT-immunoreactive fibers and GnIH cell bodies were observed in the DMN (Figures $4 D-G$ ). To study the effect of social isolation on the serotonergic regulation of GnIH cells, close juxtapositions between 5-HT-immunoreactive fibers and $\mathrm{GnIH}$ cell bodies was determined and analyzed using a laser scanning confocal microscope. The percentage of 5-HT-immunoreactive fibers in close juxtapositions to GnIH cells in the entire DMN and DTM was significantly decreased in isolated males compared with group-housed control males (control: $13.96 \pm 3.05 \%$ and isolated: $5.6 \pm 0.7 \%, p<0.05$; Figures 5 A,B). However, 5-HT fiber density per unit area in the DMN was the same in control and isolated rats (Figure 5C). Expression of the 5-HT-related genes sert and tph2 in the dorsal raphe nucleus (DR) was measured using quantitative real-time PCR. There were no differences in the levels of sert mRNA expression between control and socially isolated rats. However, tph 2 mRNA expression was significantly lower in socially isolated rats $(n=6)$ compared with controls $(n=6$; control: $1 \pm 0.22$ and isolated: $0.3 \pm 0.11, p<0.05$; Figure 5D).

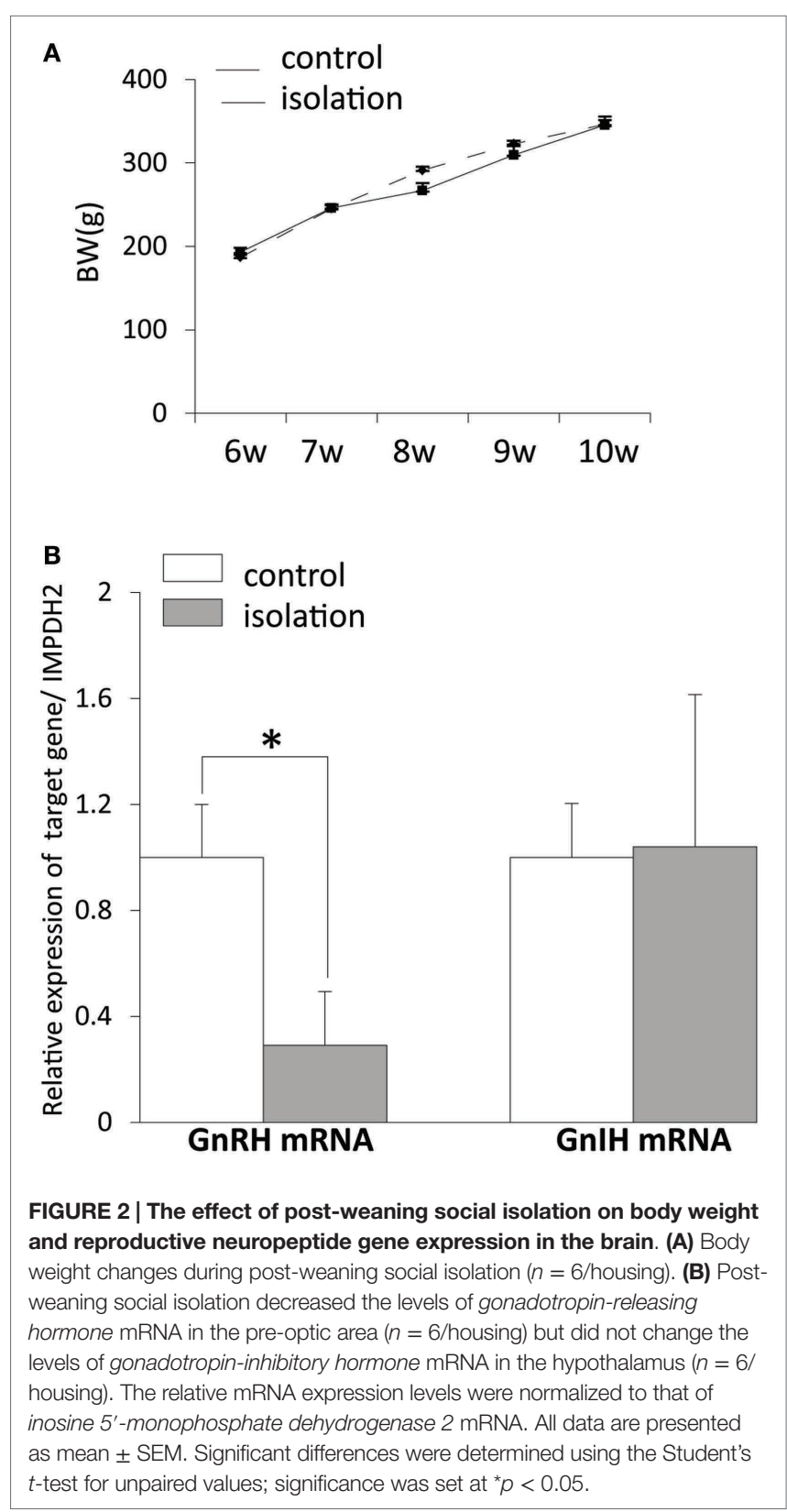


A

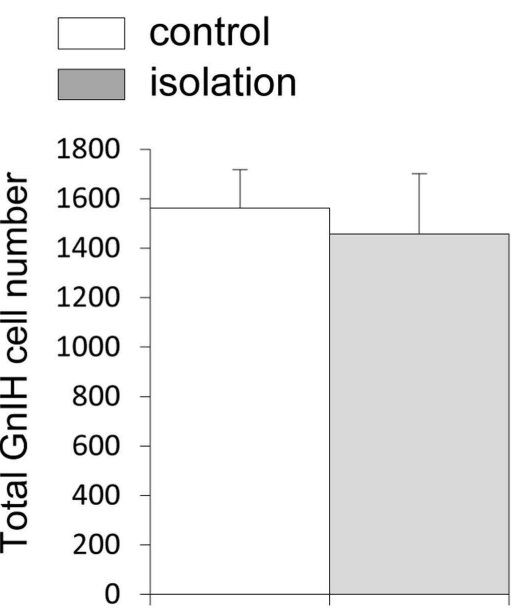

C

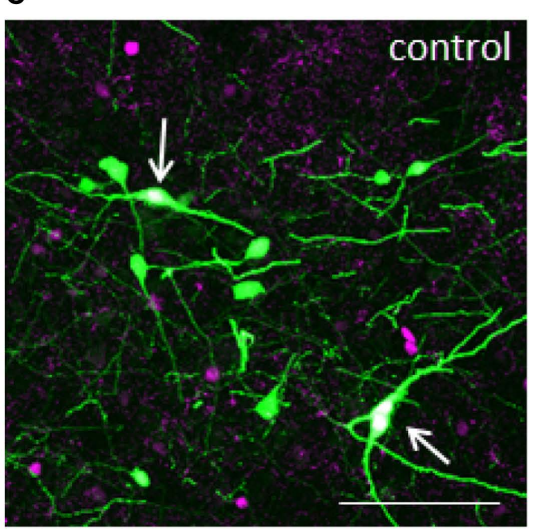

B

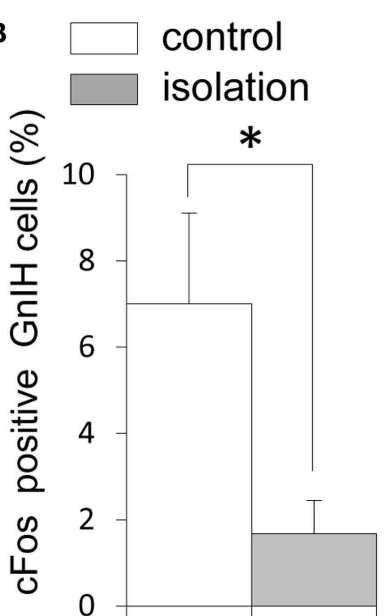

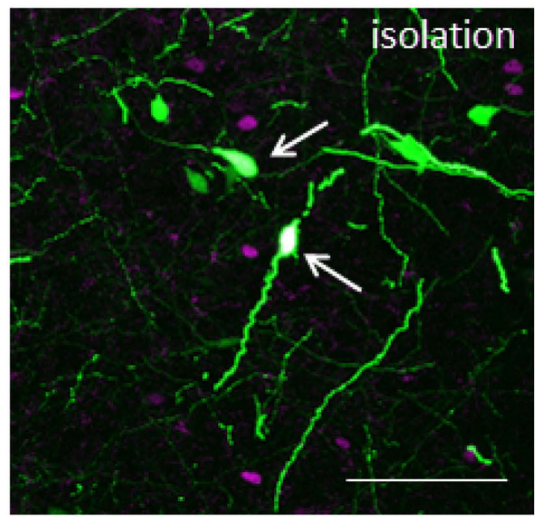

FIGURE 3 | The effect of post-weaning social isolation on enhanced green fluorescent protein-gonadotropin-inhibitory hormone neurons in the dorsomedial hypothalamic nucleus. (A) Total number of gonadotropin-inhibitory hormone (GnlH) cells in the dorsomedial hypothalamic nucleus (DMN) of control and isolated male rats (control $=14$ and isolated $=11)$. (B) Percentage of $c$-Fos-positive GnlH neurons in the DMN of control and isolated male rats. Data represent the mean \pm SEM for each group. ${ }^{*} p<0.05$. (C) Confocal images of enhanced green fluorescent protein (EGFP)-GnlH cells expressing c-Fos protein (white, indicated by arrows), EGFP-GnlH neurons (green), and red c-Fos protein (magenta) in control (left panel) and isolated (right panel) male rats. Scale bar: 100 um.

\section{DISCUSSION}

In this study, we showed that post-weaning social isolation impairs GnIH neuronal activity and the serotonergic system in the DMN, which may contribute to the deregulation of $\mathrm{GnRH}$ neuronal activity in the POA and sexual dysfunction.

\section{Social Isolation, Behavior, and the Serotonin System}

It is established that post-weaning isolation for 6 weeks from postnatal day (P) 21 (the time of weaning) has serious consequences for brain development, causing alterations in neurotransmission and behavioral abnormalities (aggression, anxiety, and depression) in rodents $(20,34,35)$. This suggests that social stimuli received after weaning are critical to the development of social behaviors and related neuronal circuits. We observed a daily variation in anxiety-like behavior in both group-housed and socially isolated rats. Importantly, during the dark phase, anxiety-like behaviors were observed in socially isolated rats. However, total locomotor activity was unaffected by group or socially isolated housing. These data suggest that the anxiogenic effect of postweaning social isolation could depend on light conditions and their effect on circadian rhythm. Indeed, disrupted sleep patterns are evident in socially isolated rats (36).

The total time spent immobile (a parameter of depressive-like behavior) is unaffected by post-weaning social isolation in rats (37). Several studies have shown that social isolation increases despair-like immobility (38-40) and immobile time in male rats (41). These conflicting results may be explained by differences between rat strains and the duration of social isolation. Furthermore, in this study, post-weaning isolation resulted in a decreased sucrose intake and reduced preference for sucrose. This anhedonia-like phenotype induced by social isolation can be reversed by treatment with the antidepressant imipramine in male rats (30), suggesting that it is mediated by the 5-HT pathway. For the first time, we show that post-weaning social isolation specifically decreases 5 -HT fiber projections to the $\mathrm{DMN}$; this may, in turn, cause the downregulation of sert gene 

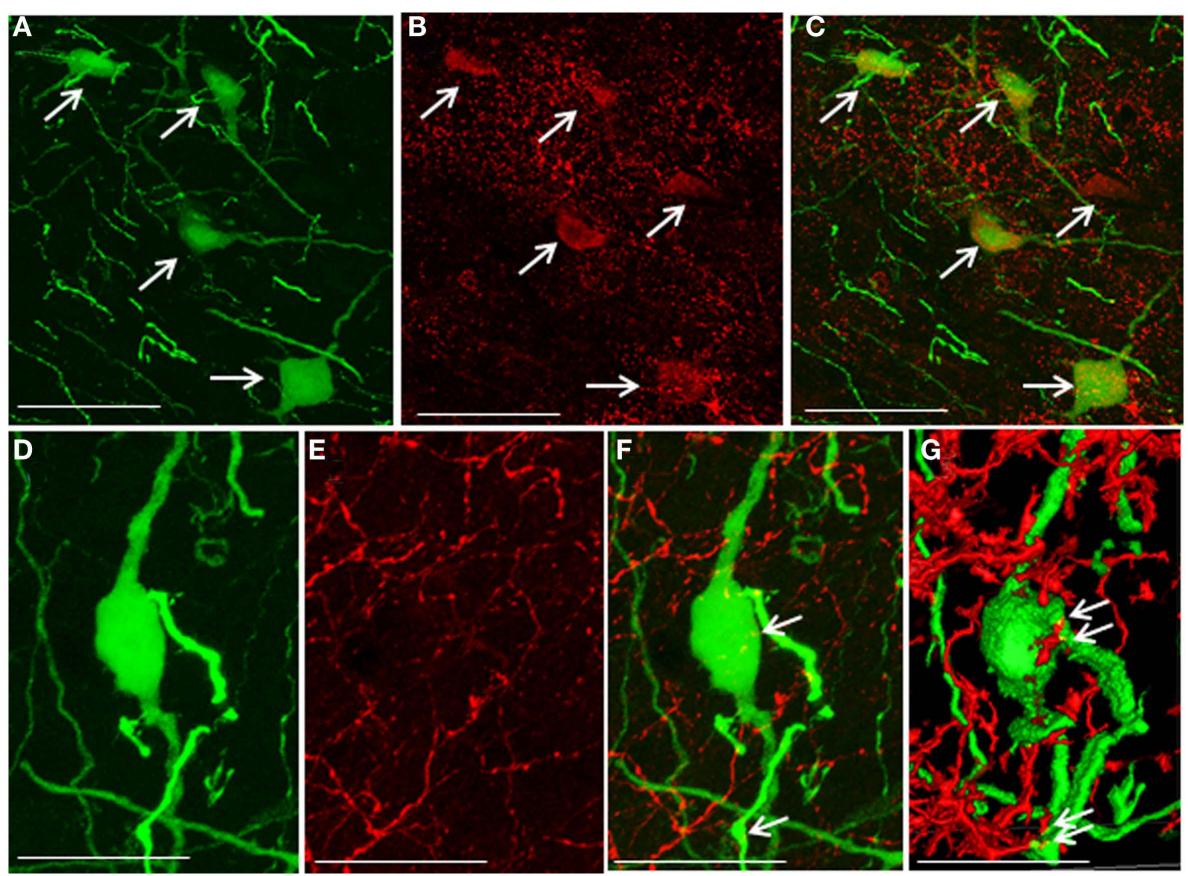

FIGURE 4 | Co-localization of 5-hydroxytryptamine fibers and the 5-hydroxytryptamine ${ }_{2 \mathrm{~A}}$ receptor in enhanced green fluorescent proteingonadotropin-inhibitory hormone cells in the dorsomedial hypothalamic nucleus. (A) Enhanced green fluorescent protein (EGFP)-gonadotropin-inhibitory hormone $(\mathrm{GnlH})$ cells and fibers (green), (B) 5-hydroxytryptamine ${ }_{2 \mathrm{~A}}\left(5-\mathrm{HT}_{2 \mathrm{~A}}\right.$ )-immunostained neurons (red), and (C) EGFP-GnlH cells expressing 5-HT $2 \mathrm{~A}$ (yellow/ orange) and 5-HT $2 \mathrm{~A}$-immunostained neurons (red) in the dorsomedial hypothalamic nucleus (DMN). (D) EGFP-GnlH neurons (green), (E) 5-hydroxytryptamine (5-HT)-immunostained fibers (red), and (F) 5-HT in close juxtapositions in EGFP-GnlH neurons or fibers (yellow dot, indicated by arrows). (G) 3D images of 5-HT in close juxtapositions in EGFP-GnIH neurons or fibers (yellow dot, indicated by arrows) in the DMN. Scale bars: (A-C), $50 \mu \mathrm{m}$; (D-G), $20 \mu \mathrm{m}$.

expression in the DR, where 5-HT neurons are primarily located. This is supported by the decrease in central 5-HT and 5-HT receptors evident in socially isolated animals during episodes of increased anxiety $(27,42)$. Although evidence of serotonergic and 5-HT receptor activity in the DMN remains inconclusive, serotonergic projections to DMN neurons have been reported (43). Indeed, in this study, we found that $5-\mathrm{HT}_{2 \mathrm{~A}}$ is co-localized in $\mathrm{GnIH}$ neurons in rats. Although the magnitude of changes in $5-\mathrm{HT}_{2 \mathrm{C}}$ in $\mathrm{GnIH}$ neurons in socially isolated rats is unknown, antagonists of $5-\mathrm{HT}_{2 \mathrm{C}}$ receptors reportedly increase sucrose preference (44). Several 5-HT receptor types, including $5-\mathrm{HT}_{2 \mathrm{C}}$, are expressed in GnIH neurons in the DMN of female mice (8). Therefore, the alteration of serotonergic signaling in the DMN may underlie the reduced preference for sucrose in socially isolated rats. Therefore, GnIH neurons and other neurons in the DMN may be targets of the circuitry for anxiety and anhedonia that mediates serotonergic activity following post-weaning social isolation.

\section{Social Isolation and Reproduction}

Reproductive senescence can be caused by factors related to the social environment. Stress in early life delays pubertal onset, lowers GnRH expression, lowers testosterone synthesis, and impairs sexual behavior, all of which eventually lead to sexual dysfunction in mammals $(31,32,45-47)$. Post-weaning social isolation impairs male sexual behavior, as indicated by an increased latency of ejaculation during adulthood $(30,48)$. GnRH expression and release from the POA is a key regulator of gonadotropin release and reproductive behavior. Our results show that post-weaning social isolation decreases the expression of $\mathrm{GnRH}$ mRNA in male rats, which could lead to sexual dysfunction.

\section{Social Isolation and Gonadotropin- Inhibitory Hormone Neuronal Activity}

This study is the first to demonstrate GnIH neuronal activity following post-weaning social isolation. Although it is established that $\mathrm{GnIH}$ inhibits $\mathrm{GnRH}$ neuronal activity $(7,9)$ and $\mathrm{GnRH}$ induced-LH release by the pituitary gland (5), we found that postweaning social isolation decreases both GnRH mRNA expression and GnIH neuronal activity. Thus, both the GnRH and GnIH systems are down regulated following post-weaning social isolation. In rats, neural activity and the release of GnRH are increased just before and after puberty in the POA (49), which coincides with pubertal processes, such as changes in $\gamma$-aminobutyric acid (GABA) and glutamate levels (50). Morphological changes, such as structural remodeling of the dendrites of $\mathrm{GnRH}$ neurons, are the key change during puberty (51). Although the timing of the formation of inhibitory $\mathrm{GnIH}$ neuronal inputs to $\mathrm{GnRH}$ neurons during the post-natal period remains unknown, a lack of social stimuli pre- and post-puberty may have an impact on 
A

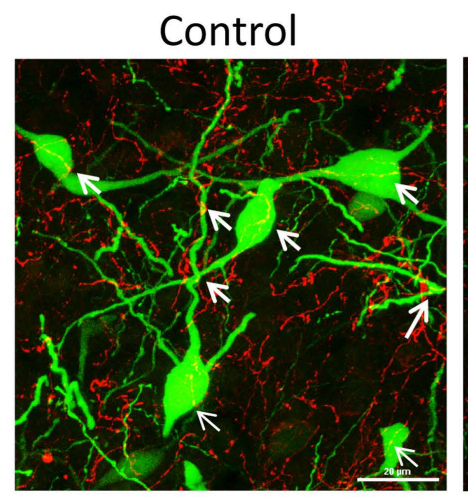

B

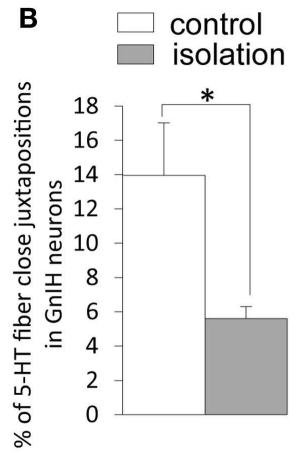

C
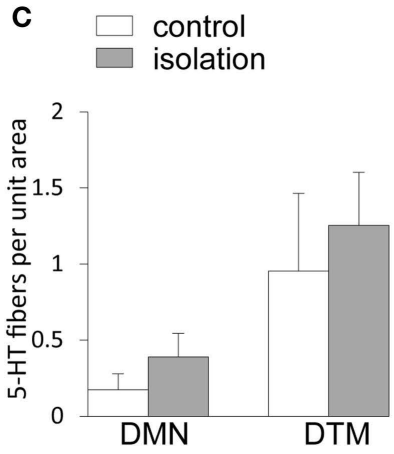

Isolation

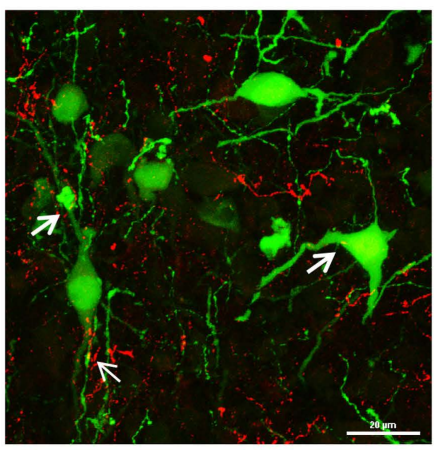

D $\square$ control

isolation

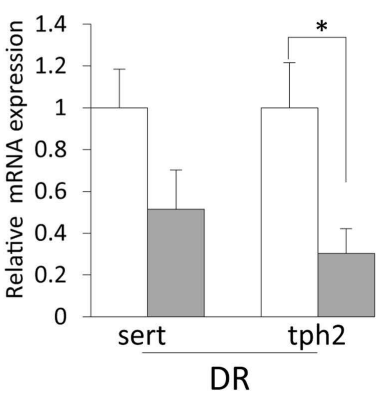

FIGURE 5 | The effect of post-weaning social isolation on 5-hydroxytryptamine projections in enhanced green fluorescent protein-gonadotropininhibitory hormone neurons in the dorsomedial hypothalamic nucleus and 5-hydroxytryptamine-related gene expression in the dorsal raphe nucleus (A). Confocal images of gonadotropin-inhibitory hormone $(\mathrm{Gn} / \mathrm{H})$ cells expressing 5-hydroxytryptamine (5-HT) fiber juxtapositions (enhanced green fluorescent protein-GnlH neurons, green; 5-HT, red; fiber juxtapositions; yellow indicated by arrows) in control (left panel) and isolated (right panel) male rats. Scale bar: $20 \mu \mathrm{m}$. (B) Percentage of 5-HT fibers in close juxtapositions in GnlH cells in the dorsomedial hypothalamic nucleus (DMN) of control and isolated male rats (control $=6$ and isolated =6). (C) $5-\mathrm{HT}$ immunostaining density per unit area in the DMN and dorsal tuberomammillary nucleus of control and isolated male rats. (D) Relative serotonin transporter and tryptophan hydroxylase 2 mRNA expression was normalized to that of the housekeeping gene inosine $5^{\prime}$-monophosphate dehydrogenase 2 mRNA in the dorsal raphe nucleus of control and socially isolated rats $\left(n=6 /\right.$ housing). Data are presented as mean \pm SEM for each group. ${ }^{*} p<0.05$.

the formation of GnIH inputs to GnRH neurons. Post-weaning social isolation may disturb normal GnIH-GnRH neuronal signaling during pubertal development, which may result in reduced expression of $\mathrm{GnRH}$ and $\mathrm{GnIH}$ in the brain.

Accumulated evidence from recent studies $(8,10,12)$ shows that stress increases $\mathrm{GnIH}$ expression, with an associated suppression of the hypothalamic-pituitary-gonadal axis suggesting that the inhibitory effect of stress on reproductive function may be mediated by the $\mathrm{GnIH}$ system. Post-weaning social isolation causes hypofunction of the HPA axis in adult rats, suggesting that the HPA axis becomes desensitized to stressful stimuli (52). GnIH neurons are sensitive to stress (10-12); thus, in socially isolated rats, they may also become desensitized, as implied by their low neuronal activity. Long-term social isolation lowers GnRH mRNA expression in the POA during adulthood; therefore, inhibitory GnIH signaling may be reduced as a result of short-loop negative feedback from GnRH neurons. Post-weaning social isolation may disrupt the normal development and balance of the GnIH-GnRH neuronal pathway for reproductive activity.

We did not observe any erroneous positioning of EGFPGnIH neurons in the DMN of socially isolated rats. Likewise, social isolation had no effect on the total number of EGFP-GnIH cells. During development, GnIH expression starts at embryonic days (E) 13-14. GnIH neurons migrate to the dorsal and ventral regions of the third ventricle at E16-17 and establish their positions in the medial hypothalamus by E18 $(53,54)$. GnIH neurons send ascending and descending projections to other regions of the brain by $\mathrm{P} 1$ and the $\mathrm{GnIH}$ neuronal system is almost completely formed by P28 $(3,53)$. Our study shows that the development and positioning of GnIH neurons in the DMN during the prenatal period is not altered by post-weaning (after P21) social isolation.

\section{Social Isolation and the Serotonergic Regulation of Gonadotropin-Inhibitory Hormone Neurons}

5-HT-immunoreactive fibers form close juxtapositions to $\mathrm{GnIH}$ neurons in the DMN of the rat brain. The DMN receives 5-HT fibers and terminals through the medial forebrain bundle from 5-HT nerve cell bodies of the DR (55). Our findings related to $5-\mathrm{HT}_{2 \mathrm{~A}}$, and those of our previous study (14), show that 5-HT 
receptors are co-expressed in $\mathrm{GnIH}$ neurons in female mice. Additionally, administration of citalopram increases the number of GnIH neurons in the DMN and the density of GnIH fibers in the POA (14), supporting the concept that $\mathrm{GnIH}$ is under direct serotonergic control. The significant decrease in c-Fos expression evident in GnIH neurons, combined with the decreased 5-HT innervation of GnIH neurons in socially isolated animals, suggest a reduction in GnIH neuronal activity. Early environmental manipulations impair long-term synaptic potentiation (56). The decrease in 5-HT fiber juxtapositions to $\mathrm{GnIH}$ neurons reflects neuroanatomical adaptation of hypothalamic neuronal circuits in response to a deprived social environment in early life. 5-HT synaptogenesis is important for brain 5-HT concentration during the critical period of brain development (57). Moreover, 5-HT receptor complements are established between $\mathrm{P} 30-50$ in rats $(58,59)$. Thus, the reduction in 5-HT fiber juxtapositions to GnIH neurons following post-weaning social isolation may delay post-natal maturation, which may weaken the strength of existing synapses.

\section{CONCLUSION}

In this study, we showed that post-weaning social isolation enhances anxiety-like behavior and an anhedonia-like phenotype that is related to altered sert expression in the serotonergic system.

\section{REFERENCES}

1. Tsutsui K. A new key neurohormone controlling reproduction, gonadotropin-inhibitory hormone $(\mathrm{GnIH})$ : biosynthesis, mode of action and functional significance. Prog Neurobiol (2009) 88:76-88. doi:10.1016/j. pneurobio.2009.02.003

2. Hinuma S, Shintani Y, Fukusumi S, Iijima N, Matsumoto Y, Hosoya $M$, et al. New neuropeptides containing carboxy-terminal RFamide and their receptor in mammals. Nat Cell Biol (2000) 2:703-8. doi:10.1038/35036326

3. Kriegsfeld LJ, Mei DF, Bentley GE, Ubuka T, Mason AO, Inoue K, et al. Identification and characterization of a gonadotropin-inhibitory system in the brains of mammals. Proc Natl Acad Sci U S A (2006) 103:2410-5. doi:10.1073/ pnas. 0511003103

4. Soga T, Kitahashi T, Clarke IJ, Parhar IS. Gonadotropin-inhibitory hormone promoter-driven enhanced green fluorescent protein expression decreases during aging in female rats. Endocrinology (2014) 155:1944-55. doi:10.1210/ en.2013-1786

5. Johnson MA, Tsutsui K, Fraley GS. Rat RFamide-related peptide-3 stimulates GH secretion, inhibits LH secretion, and has variable effects on sex behavior in the adult male rat. Horm Behav (2007) 51:171-80. doi:10.1016/j. yhbeh.2006.09.009

6. Anderson GM, Relf HL, Rizwan MZ, Evans JJ. Central and peripheral effects of RFamide-related peptide- 3 on luteinizing hormone and prolactin secretion in rats. Endocrinology (2009) 150:1834-40. doi:10.1210/en.2008-1359

7. Wu M, Dumalska I, Morozova E, Van Den Pol AN, Alreja M. Gonadotropin inhibitory hormone inhibits basal forebrain vGluT2-gonadotropin-releasing hormone neurons via a direct postsynaptic mechanism. J Physiol (2009) 587:1401-11. doi:10.1113/jphysiol.2008.166447

8. Soga T, Dalpatadu SL, Wong DW, Parhar IS. Neonatal dexamethasone exposure down-regulates GnRH expression through the $\mathrm{GnIH}$ pathway in female mice. Neuroscience (2012) 218:56-64. doi:10.1016/j. neuroscience.2012.05.023

9. Ducret E, Anderson GM, Herbison AE. RFamide-related peptide-3, a mammalian gonadotropin-inhibitory hormone ortholog, regulates
Furthermore, we demonstrated that post-weaning social isolation reduces GnIH neuronal activity and decreases 5-HT fiber juxtapositions to GnIH neurons, suggesting that serotonergic regulation may participate in $\mathrm{GnIH}$ signaling to accomplish normal $\mathrm{GnRH}$ neuronal activity and reproductive function. Although a complex molecular and neuronal mechanism is involved in post-weaning social isolation-induced reproductive dysfunction, altered serotonergic activity may be one factor that mediates GnIH-GnRH signaling in the brain. Our findings characterize the long consensus on the negative effects of post-weaning social isolation and provide insights into the neuronal and molecular mechanisms underlying the serotonergic regulation of $\mathrm{GnIH}$.

\section{FUNDING}

This work was supported by research grant from Monash University, Malaysia (TS01-10, TS, IP) and eScienceFund from The Ministry of Science, Technology \& Innovation (02-02-10SF0164 TS, IP).

\section{SUPPLEMENTARY MATERIAL}

The Supplementary Material for this article can be found online at http://journal.frontiersin.org/article/10.3389/ fendo.2015.00172

gonadotropin-releasing hormone neuron firing in the mouse. Endocrinology (2009) 150:2799-804. doi:10.1210/en.2008-1623

10. Kirby ED, Geraghty AC, Ubuka T, Bentley GE, Kaufer D. Stress increases putative gonadotropin inhibitory hormone and decreases luteinizing hormone in male rats. Proc Natl Acad Sci U S A (2009) 106:11324-9. doi:10.1073/ pnas.0901176106

11. Gojska NM, Belsham DD. Glucocorticoid receptor-mediated regulation of Rfrp (GnIH) and Gpr147 (GnIH-R) synthesis in immortalized hypothalamic neurons. Mol Cell Endocrinol (2014) 384:23-31. doi:10.1016/j.mce.2013.12.015

12. Son YL, Ubuka T, Narihiro M, Fukuda Y, Hasunuma I, Yamamoto K, et al. Molecular basis for the activation of gonadotropin-inhibitory hormone gene transcription by corticosterone. Endocrinology (2014) 155:1817-26. doi:10.1210/en.2013-2076

13. Marvin E, Scrogin K, Dudas B. Morphology and distribution of neurons expressing serotonin 5-HT1A receptors in the rat hypothalamus and the surrounding diencephalic and telencephalic areas. J Chem Neuroanat (2010) 39:235-41. doi:10.1016/j.jchemneu.2010.01.003

14. Soga T, Wong DW, Clarke IJ, Parhar IS. Citalopram (antidepressant) administration causes sexual dysfunction in male mice through RF-amide related peptide in the dorsomedial hypothalamus. Neuropharmacology (2010) 59:77-85. doi:10.1016/j.neuropharm.2010.03.018

15. Lowry CA, Plant A, Shanks N, Ingram CD, Lightman SL. Anatomical and functional evidence for a stress-responsive, monoamine-accumulating area in the dorsomedial hypothalamus of adult rat brain. Horm Behav (2003) 43:254-62. doi:10.1016/S0018-506X(02)00009-0

16. Gasser PJ, Lowry CA, Orchinik M. Corticosterone-sensitive monoamine transport in the rat dorsomedial hypothalamus: potential role for organic cation transporter 3 in stress-induced modulation of monoaminergic neurotransmission. J Neurosci (2006) 26:8758-66. doi:10.1523/JNEUROSCI.0570-06.2006

17. Angoa-Perez M, Kuhn DM. Neuroanatomical dichotomy of sexual behaviors in rodents: a special emphasis on brain serotonin. Behav Pharmacol (2015) 26:595-606. doi:10.1097/FBP.0000000000000157

18. Serra M, Pisu MG, Floris I, Biggio G. Social isolation-induced changes in the hypothalamic-pituitary-adrenal axis in the rat. Stress (2005) 8:259-64. doi:10.1080/10253890500495244 
19. Butler TR, Ariwodola OJ, Weiner JL. The impact of social isolation on HPA axis function, anxiety-like behaviors, and ethanol drinking. Front Integr Neurosci (2014) 7:102. doi:10.3389/fnint.2013.00102

20. Lapiz MD, Fulford A, Muchimapura S, Mason R, Parker T, Marsden CA. Influence of postweaning social isolation in the rat on brain development, conditioned behavior, and neurotransmission. Neurosci Behav Physiol (2003) 33:13-29. doi:10.1023/A:1021171129766

21. Jones GH, Hernandez TD, Kendall DA, Marsden CA, Robbins TW. Dopaminergic and serotonergic function following isolation rearing in rats: study of behavioural responses and postmortem and in vivo neurochemistry. Pharmacol Biochem Behav (1992) 43:17-35. doi:10.1016/0091-3057(92)90635-S

22. Bickerdike MJ, Wright IK, Marsden CA. Social isolation attenuates rat forebrain 5-HT release induced by $\mathrm{KCI}$ stimulation and exposure to a novel environment. Behav Pharmacol (1993) 4:231-6. doi:10.1097/00008877-199306000-00005

23. Fulford AJ, Marsden CA. Effect of isolation-rearing on noradrenaline release in rat hypothalamus and hippocampus in vitro. Brain Res (1997) 748:93-9. doi:10.1016/S0006-8993(96)01279-6

24. Muchimapura S, Mason R, Marsden CA. Effect of isolation rearing on pre- and post-synaptic serotonergic function in the rat dorsal hippocampus. Synapse (2003) 47:209-17. doi:10.1002/syn.10167

25. Yates G, Panksepp J, Ikemoto S, Nelson E, Conner R. Social isolation effects on the "behavioral despair" forced swimming test: effect of age and duration of testing. Physiol Behav (1991) 49:347-53. doi:10.1016/0031-9384(91)90055-S

26. Wongwitdecha N, Marsden CA. Social isolation increases aggressive behaviour and alters the effects of diazepam in the rat social interaction test. Behav Brain Res (1996) 75:27-32. doi:10.1016/0166-4328(96)00181-7

27. Heidbreder CA, Weiss IC, Domeney AM, Pryce C, Homberg J, Hedou G, et al. Behavioral, neurochemical and endocrinological characterization of the early social isolation syndrome. Neuroscience (2000) 100:749-68. doi:10.1016/ S0306-4522(00)00336-5

28. Wilhelmsson M, Larsson K. The development of sexual behavior in anosmic male rats reared under various social conditions. Physiol Behav (1973) 11:227-32. doi:10.1016/0031-9384(73)90354-5

29. Cooke BM, Chowanadisai W, Breedlove SM. Post-weaning social isolation of male rats reduces the volume of the medial amygdala and leads to deficits in adult sexual behavior. Behav Brain Res (2000) 117:107-13. doi:10.1016/ S0166-4328(00)00301-6

30. Wallace DL, Han MH, Graham DL, Green TA, Vialou V, Iniguez SD, et al. CREB regulation of nucleus accumbens excitability mediates social isolation-induced behavioral deficits. Nat Neurosci (2009) 12:200-9. doi:10.1038/ nn. 2257

31. Lupo Di Prisco C, Dessi-Fulgheri F, Travaglini P. Effect of long-term isolation of the rat on in vitro biosynthesis of gonadal steroids from dehydroepiandrosterone. Horm Res (1975) 6:336-41. doi:10.1159/000178683

32. Sayegh JF, Kobor G, Lajtha A, Vadasz C. Effects of social isolation and the time of day on testosterone levels in plasma of C57BL/6By and BALB/cBy mice. Steroids (1990) 55:79-82. doi:10.1016/0039-128X(90)90029-B

33. Eisenberg E, Levanon EY. Human housekeeping genes are compact. Trends Genet (2003) 19:362-5. doi:10.1016/S0168-9525(03)00140-9

34. Einon DF, Morgan MJ. A critical period for social isolation in the rat. Dev Psychobiol (1977) 10:123-32. doi:10.1002/dev.420100205

35. Wright IK, Upton N, Marsden CA. Resocialisation of isolation-reared rats does not alter their anxiogenic profile on the elevated X-maze model of anxiety. Physiol Behav (1991) 50:1129-32. doi:10.1016/0031-9384(91)90572-6

36. Esquifino AI, Cano P, Jimenez-Ortega V, Fernandez-Mateos P, Cardinali DP. Neuroendocrine-immune correlates of circadian physiology: studies in experimental models of arthritis, ethanol feeding, aging, social isolation, and calorie restriction. Endocrine (2007) 32:1-19. doi:10.1007/s12020-007-9009-y

37. Hall FS, Huang S, Fong GF, Pert A. The effects of social isolation on the forced swim test in Fawn hooded and Wistar rats. J Neurosci Methods (1998) 79:47-51. doi:10.1016/S0165-0270(97)00155-6

38. Brenes Saenz JC, Villagra OR, Fornaguera Trias J. Factor analysis of forced swimming test, sucrose preference test and open field test on enriched, social and isolated reared rats. Behav Brain Res (2006) 169:57-65. doi:10.1016/j. bbr.2005.12.001
39. Brenes JC, Rodriguez O, Fornaguera J. Differential effect of environment enrichment and social isolation on depressive-like behavior, spontaneous activity and serotonin and norepinephrine concentration in prefrontal cortex and ventral striatum. Pharmacol Biochem Behav (2008) 89:85-93. doi:10.1016/j.pbb.2007.11.004

40. Kokare DM, Dandekar MP, Singru PS, Gupta GL, Subhedar NK. Involvement of alpha-MSH in the social isolation induced anxiety- and depression-like behaviors in rat. Neuropharmacology (2010) 58:1009-18. doi:10.1016/j. neuropharm.2010.01.006

41. Simpson J, Bree D, Kelly JP. Effect of early life housing manipulation on baseline and drug-induced behavioural responses on neurochemistry in the male rat. Prog Neuropsychopharmacol Biol Psychiatry (2012) 37:252-63. doi:10.1016/j.pnpbp.2012.02.008

42. Muchimapura S, Marsden CA. The effect of social isolation rearing on the development of the hippocampus and serotonergic function. Thai J Physiol Sci (2004) 17:1-8. doi:10.1016/j.neuroscience.2009.06.017

43. Biagioni AF, De Freitas RL, Da Silva JA, De Oliveira RC, De Oliveira R, Alves VM, et al. Serotonergic neural links from the dorsal raphe nucleus modulate defensive behaviours organised by the dorsomedial hypothalamus and the elaboration of fear-induced antinociception via locus coeruleus pathways. Neuropharmacology(2013)67:379-94.doi:10.1016/j.neuropharm.2012.10.024

44. Der-Avakian A, Markou A. The neurobiology of anhedonia and other reward-related deficits. Trends Neurosci (2012) 35:68-77. doi:10.1016/j. tins.2011.11.005

45. Page KC, Sottas CM, Hardy MP. Prenatal exposure to dexamethasone alters leydig cell steroidogenic capacity in immature and adult rats. J Androl (2001) 22:973-80. doi:10.1002/j.1939-4640.2001.tb03438.x

46. Rhees RW, Lephart ED, Eliason D. Effects of maternal separation during early postnatal development on male sexual behavior and female reproductive function. Behav Brain Res (2001) 123:1-10. doi:10.1016/ S0166-4328(00)00381-8

47. Lim WL, Soga T, Parhar IS. Maternal dexamethasone exposure during pregnancy in rats disrupts gonadotropin-releasing hormone neuronal development in the offspring. Cell Tissue Res (2014) 355:409-23. doi:10.1007/ s00441-013-1765-9

48. Barrot M, Wallace DL, Bolanos CA, Graham DL, Perrotti LI, Neve RL, et al. Regulation of anxiety and initiation of sexual behavior by CREB in the nucleus accumbens. Proc Natl Acad Sci U S A (2005) 102:8357-62. doi:10.1073/ pnas.0500587102

49. Bourguignon JP, Gerard A, Franchimont P. Maturation of the hypothalamic control of pulsatile gonadotropin-releasing hormone secretion at onset of puberty: II. Reduced potency of an inhibitory autofeedback. Endocrinology (1990) 127:2884-90. doi:10.1210/endo-127-6-2884

50. Clarkson J, Herbison AE. Development of GABA and glutamate signaling at the GnRH neuron in relation to puberty. Mol Cell Endocrinol (2006) 25(4-255):32-8. doi:10.1016/j.mce.2006.04.036

51. Hemond PJ, O'boyle MP, Hemond Z, Gay VL, Suter K. Changes in dendritic architecture: not your "usual suspect" in control of the onset of puberty in male rats. Front Endocrinol (2013) 4:78. doi:10.3389/fendo.2013.00078

52. Sanchez MM, Aguado F, Sanchez-Toscano F, Saphier D. Neuroendocrine and immunocytochemical demonstrations of decreased hypothalamo-pituitary-adrenal axis responsiveness to restraint stress after long-term social isolation. Endocrinology (1998) 139:579-87. doi:10.1210/en.139.2.579

53. Yano T, Iijima N, Hinuma S, Tanaka M, Ibata Y. Developmental expression of RFamide-related peptides in the rat central nervous system. Brain Res Dev Brain Res (2004) 152:109-20. doi:10.1016/j.devbrainres.2004.06.008

54. Legagneux K, Bernard-Franchi G, Poncet F, La Roche A, Colard C, Fellmann $\mathrm{D}$, et al. Distribution and genesis of the RFRP-producing neurons in the rat brain: comparison with melanin-concentrating hormone- and hypocretin-containing neurons. Neuropeptides (2009) 43:13-9. doi:10.1016/j. npep.2008.11.001

55. Steinbusch HW, Nieuwenhuys R. Localization of serotonin-like immunoreactivity in the central nervous system and pituitary of the rat, with special references to the innervation of the hypothalamus. Adv Exp Med Biol (1981) 133:7-35. doi:10.1007/978-1-4684-3860-4_1

56. Herpfer I, Hezel H, Reichardt W, Clark K, Geiger J, Gross CM, et al. Early life stress differentially modulates distinct forms of brain plasticity in young and adult mice. PLoS One (2012) 7:e46004. doi:10.1371/journal.pone.0046004 
57. Mazer C, Muneyyirci J, Taheny K, Raio N, Borella A, Whitaker-Azmitia P. Serotonin depletion during synaptogenesis leads to decreased synaptic density and learning deficits in the adult rat: a possible model of neurodevelopmental disorders with cognitive deficits. Brain Res (1997) 760:68-73. doi:10.1016/ S0006-8993(97)00297-7

58. Karki NT, Kuntzman R, Brodie BB. Norepinephrine and serotonin brain levels at various stages of ontogenetic development. Fed Proc (1960) 19:202.

59. Coyle JT, Henry D. Catecholamines in fetal and newborn rat brain. J Neurochem (1973) 21:61-7. doi:10.1111/j.1471-4159.1973.tb04225.x
Conflict of Interest Statement: The authors declare that the research was conducted in the absence of any commercial or financial relationships that could be construed as a potential conflict of interest.

Copyright $\odot 2015$ Soga, Teo, Cham, Idris and Parhar. This is an open-access article distributed under the terms of the Creative Commons Attribution License (CC BY). The use, distribution or reproduction in other forums is permitted, provided the original author(s) or licensor are credited and that the original publication in this journal is cited, in accordance with accepted academic practice. No use, distribution or reproduction is permitted which does not comply with these terms. 